Article

\title{
Heat Shock Transcription Factor CgHSF1 Is Required for Melanin Biosynthesis, Appressorium Formation, and Pathogenicity in Colletotrichum gloeosporioides
}

\author{
Xuesheng Gao ${ }^{1,2, \dagger}$, Qiannan Wang ${ }^{1,2, \dagger}$, Qingdeng Feng ${ }^{1}$, Bei Zhang ${ }^{1,2}$, Chaozu He ${ }^{1,2}$, Hongli Luo ${ }^{1,2, *}$ \\ and Bang An 1,2,*(i) \\ 1 Hainan Key Laboratory for Sustainable Utilization of Tropical Bioresource, College of Tropical Crops, \\ Hainan University, Haikou 570228, China; 19095131210013@hainanu.edu.cn (X.G.); \\ wangqiannan@hainanu.edu.cn (Q.W.); fqd2429009287@163.com (Q.F.); zhangbei@hainanu.edu.cn (B.Z.); \\ czhe@hainanu.edu.cn (C.H.) \\ 2 Sanya Nanfan Research Institute, Hainan University, Sanya 572025, China \\ * Correspondence: hlluo@hainanu.edu.cn (H.L.); anbang@hainanu.edu.cn (B.A.) \\ + These authors contributed equally to this work.
}

Citation: Gao, X.; Wang, Q.; Feng, Q.; Zhang, B.; He, C.; Luo, H.; An, B. Heat Shock Transcription Factor CgHSF1 Is Required for Melanin Biosynthesis, Appressorium Formation, and Pathogenicity in Colletotrichum gloeosporioides. J. Fungi 2022, 8, 175. https://doi.org/ $10.3390 /$ jof 8020175

Academic Editors: Andrzej

K. Kononowicz and Violetta

Katarzyna Macioszek

Received: 26 November 2021

Accepted: 7 February 2022

Published: 11 February 2022

Publisher's Note: MDPI stays neutral with regard to jurisdictional claims in published maps and institutional affiliations.

Copyright: (C) 2022 by the authors. Licensee MDPI, Basel, Switzerland. This article is an open access article distributed under the terms and conditions of the Creative Commons Attribution (CC BY) license (https:// creativecommons.org/licenses/by/ $4.0 /)$.

\begin{abstract}
Heat shock transcription factors (HSFs) are a family of transcription regulators. Although $\mathrm{HSFs}^{\prime}$ functions in controlling the transcription of the molecular chaperone heat shock proteins and resistance to stresses are well established, their effects on the pathogenicity of plant pathogenic fungi remain unknown. In this study, we analyze the role of CgHSF1 in the pathogenicity of Colletotrichum gloeosporioides and investigate the underlying mechanism. Failure to generate the Cghsf1 knock-out mutant suggested that the gene is essential for the viability of the fungus. Then, genetic depletion of the Cghsf1 was achieved by inserting the repressive promoter of nitrite reductase gene (PniiA) before its coding sequence. The mutant showed significantly decrease in the pathogenicity repression of appressorium formation, and severe defects in melanin biosynthesis. Moreover, four melanin synthetic genes were identified as direct targets of CgHSF1. Taken together, this work highlights the role of $\mathrm{CgHSF} 1$ in fungal pathogenicity via the transcriptional activation of melanin biosynthesis. Our study extends the understanding of fungal HSF1 proteins, especially their involvement in pathogenicity.
\end{abstract}

Keywords: HSF1; melanin; appressorium; pathogenicity; Colletotrichum gloeosporioides

\section{Introduction}

The genus Colletotrichum spp. is a group of plant pathogenic fungi that can infect a wide range of plants worldwide [1]. There is a total of 600 Colletotrichum species identified by now; among these species, Colletotrichum gloeosporioides can infect over 470 plant species and cause anthracnose diseases in both aerial plant parts and in post-harvest fruits, such as banana, mango, avocado, coffee [2].

Most of Colletotrichum species employ a hemibiotrophic lifestyle, including conidia germination, melanized appressorium formation, biotrophic intracellular hyphae, and a necrotrophic phase on dead host cells [1]. During infection processes, Colletotrichum higginsianum, Colletotrichum orbiculare, and C. gloeosporioides could adjust their strategies to switch between these stages by regulating the expression of virulence factors, such as effectors, secondary metabolite synthesis enzymes, and degradative enzymes [3,4]. In addition, a number of transcription factors (TFs) were found to play important roles in controlling the switch from non-pathogenic parasite to pathogeny in pathogenic fungi. For example, Wor1, a conserved fungal TF from Candida albicans, controls the white-opaque switching of cells and is required for virulence to humans [5,6]. In plant pathogenic fungi from the genus Fusarium, SGE1 proteins, the orthologs of Wor1, regulate effector genes and 
secondary metabolite gene clusters [7-10], and are required for parasitic growth [11]. In Botrytis cinerea, Verticillium dahliae, Zymoseptoria tritici, Ustilago maydis, and Magnaporthe oryzae, orthologs of Wor1 also participate in the regulation of the expression of effector genes and virulence to the hosts [12-16]. Some other TFs, such as the forkhead transcription factor Fox1 and zinc finger transcription factor Mzr1 of Ustilago maydis, are involved in the regulation of effector genes $[17,18]$.

Heat shock transcription factors (HSFs) are a family of transcription regulators, which were thus named for they can regulate the expression of heat shock proteins (HSPs) in cells [19,20]. Since the first discovery and being cloned in Drosophila and yeast [21,22], HSFs have been identified in a variety of species. HSFs are conserved in eukaryotes from fungi, such as Saccharomyces cerevisiae, which has only one HSF gene, to humans whose genome encodes six HSF proteins [22,23]. In plants, HSFs are a large and diverse gene family with more complex functions due to their great differences in size and sequence [24]. HSFs were originally described to recognize and specifically bind the conserved motif of the heat shock element (HSE) in the promoter region of HSP genes, thereby increasing biological resistance to heat stress, chemical stimuli, and oxidative stress [24-26]. In yeast, HSF1 is essential for survival and the modulation of chaperone levels in response to growth temperature [27]. In mouse, the HSF1-dependent expression of HSP chaperones is required to maintain redox homeostasis and to regulate antioxidative defenses [28]. Additionally, the HSFs of plants play roles in response to oxidative, heavy metals, and biotic stresses during the development of and differentiation in plants $[29,30]$. In addition to the roles in stress response, there are growing evidences indicating that HSFs play pivotal roles in development and differentiation [24,31]. For example, HSFB2a is required for gametophytic development in Arabidopsis [32]; the mouse HSF4 regulates the development of lenses [33]; especially in C. albicans, both the depletion and overexpression of HSF1 could induce the transition from yeast to filamentous growth, highlighting the key role of HSF1 in virulence [34]. However, whether HSFs are required for development and virulence of plant pathogenic fungi is still elusive.

In the present study, our goal is to investigate whether CgHSF1 is required for the pathogenicity of $C$. gloeosporioides, and to figure out the possible mechanism. We found that CgHSF1 depletion impairs the expression of melanin biosynthesis genes, compromises appressorium formation, and leads to the decrease in pathogenicity. This work provides new insight into HSF1's role in fungal pathogenicity.

\section{Materials and Methods}

\subsection{Fungal Strains and Plant Material}

C. gloeosporioides Hevea (BioSample: SAMN17266943 (https:/ / www.ncbi.nlm.nih.gov/ biosample/17266943 (accessed on 9 January 2021)) was isolated from H. brasiliensis previously and kept on potato dextrose agar medium (PDA) at $28^{\circ} \mathrm{C}$. The H. brasiliensis cultivar Reyan 7-33-97 was cultured in a glass house and used for the pathogenicity assay.

\subsection{Bioinformatics Analysis}

The amino acid sequence of CgHSF1 was searched for the conserved domains against Pfam database. The HSF1 homologues from other phytopathogenic fungi were retrieved from NCBI GenBank database, and the maximum likelihood tree was constructed using JTT + G+I model and 1000 bootstrap with MEGA 11 [35].

\subsection{Construction of the Gene Knock-Out Strain, PniiA-Cghsf1 Inducible Strain, and the GFP or FLAG Tagged Strains}

The knock-out of Cghsf1 was attempted by replacing the Cghsf1 gene with the acetolactate synthase gene (SUR) cassette from $M$. oryzae, which confers resistance to chlorimuron ethyl (a sulfonylurea herbicide). Briefly, the upstream and downstream flanking fragments of Cghsf1 were amplified from genomic DNA with TransStart ${ }^{\circledR}$ FastPfu DNA Polymerase (TransGen Biotech, Beijing, China) and cloned into the plasmid pBS-SUR [36]. Then, the 
flanking sequences together with the truncated SUR were amplified and used for protoplast transform (Supplementary Figure S1).

To modulate the expression of Cghsf1, an inducible promoter (PniiA) of nitrite reductase gene (niiA) was inserted between the coding sequence of $C g h s f 1$ and its native promoter. The hygromycin B resistance cassette (HPT) was used as the selective marker. Firstly, the upstream flanking fragments of Cghsf1 were amplified with primer pairs HSF-5F/HSFhpt$5 \mathrm{MR}$, with the reverse primer having 17 nucleotides (nts) complementary to HPT sequence; and a truncated HPT fragment was amplified with primer pairs HSFhpt-5MF/hpt-SPLR, with the forward primer having 17 nts complementary to Cghsf1; then the two fragments were ligated together via overlap PCR with the two fragments as templates. Secondly, the other truncated HPT (with primers hpt-SPLF/hptniiA-MR), the PniiA promoter (with hptniiA-MF/niiAHSF-MR), and the 800 bp nucleotides of 5' part of Cghsf1 (Cghsf1-L) sequence (with niiAHSF-MF/HSF-L-R) were amplified, and then the three fragments were fused by PCR. After that, the two fused fragments were used for protoplast transformation.

The modified plasmid pMD19-T, which contains the GFP/FLAG coding sequence, a terminator of the tryptophan synthase of Aspergillus nidulans (TtrpC), and the HPT cassette, was used to tag the CgHSF1 with GFP or FLAG. The 700 bp nucleotides of the $3^{\prime}$ part of Cghsf1 without stop codon (Cghsf1-R) were amplified with the primers HSF-R-F/HSF-R, and cloned into the plasmid right before the GFP/FLAG tag; then the fragment containing the $3^{\prime}$ part of Cghsf1, GFP/FLAG, TtrpC, and the truncated HPT was prepared by PCR using the primers HSF-R-F/hpt-SPLR. The downstream flanking fragments of Cghsf1 were amplified with hptHSF3-MF/HSF-3R, and fused with the other part truncated HPT (amplified with primers hpt-SPLF/hptHSF3-MR) using PCR. After that, the two fused fragments were used for protoplast transform (Supplementary Figures S2 and S3).

Protoplast preparation and transformation were conducted as described previously [36]. The transformants were selected by resistance to chlorimuron ethyl or hygromycin B. To verify the correct integration of the recombinant fragments into the target site of the genome, two independent PCR diagnoses were conducted with the primer pairs HSF-DF/hpt-DR and niiA-DF/HSF-L-DR, with one primer being located outside of the homologous fragments and one being located inside of the expression cassette for each primer pair. In addition, an additional PCR was conducted to confirm the correctness of the inducible expression cassette, with one primer complementary to the beginning of PniiA and the other primer complementary to the down-stream sequence of Cghsf1. Besides, the full length of Cghsf1 in the GFP/FLAG tagged strains were amplified and sequenced for correctness. After that, the heterokaryon of the correct transformants were purified by single conidia isolation. The primers used are listed in Supplementary Table S2.

\subsection{Pathogenicity Assay}

The pathogenicity assay was performed as described in our previous report [36]. C. gloeosporioides conidia were collected and resuspended in $0.5 \%(w / v)$ malt extract broth (Difco, Thermo Fisher, Waltham, MA, USA) to a final concentration of $2 \times 10^{5}$ conidia $\mathrm{mL}^{-1}$. The intact "light green" leaves were detached from a rubber tree and used for the pathogen inoculation. The leaves were divided into two groups, with one group of intact leaves and the other group of leaves being pre-wounded with a sterile needle. Then, $5 \mu \mathrm{L}$ of droplets of the conidial suspensions were inoculated onto the leaves. After that, the inoculated leaves were kept in Petri dishes with lids at $28{ }^{\circ} \mathrm{C}$ under natural illumination for $3 \mathrm{~d}$, and the disease symptoms were scored. Each treatment contained three replicates of 10 leaves, and the entire experiment was repeated 3 times.

\subsection{Quantitative RT-PCR Analysis}

For the analysis of the expression levels of CgniiA, CgniaD, and Cghsf1 in response to different nitrogen sources, $C$. gloeosporioides WT strain were cultured on a minimal medium $\left(0.5 \mathrm{~g} \mathrm{~L}^{-1} \mathrm{KCl}, 1 \mathrm{~g} \mathrm{~L}^{-1} \mathrm{KH}_{2} \mathrm{PO}_{4}, 0.5 \mathrm{~g} \mathrm{~L}^{-1} \mathrm{MgSO}_{4} \cdot 7 \mathrm{H}_{2} \mathrm{O}, 0.01 \mathrm{~g} \mathrm{~L}^{-1} \mathrm{FeSO}_{4} .7 \mathrm{H}_{2} \mathrm{O}\right.$, $20 \mathrm{~g} \mathrm{~L}^{-1}$ sucrose, $\mathrm{pH}$ 6.9) supplemented with $\mathrm{NaNO}_{3}\left(20 \mathrm{mmol} \mathrm{L}^{-1}\right)$, ammonium tartrate 
$\left(\mathrm{C}_{4} \mathrm{H}_{12} \mathrm{~N}_{2} \mathrm{O}_{6}\right)\left(10 \mathrm{mmol} \mathrm{L}^{-1}\right)$, and glutamine $\left(10 \mathrm{mmol} \mathrm{L}^{-1}\right)$ as nitrogen sources. The expression levels of Cghsf1 in the repressive mutant strain during in vitro and in planta stages were also assayed. For the collection of in vitro samples, conidia were inoculated into the liquid minimal medium supplemented with different nitrogen sources at a concentration of $10^{6}$ conidia $\mathrm{mL}^{-1}$; after incubation at $160 \mathrm{rpm}, 28^{\circ} \mathrm{C}$ for $1 \mathrm{~d}$, the mycelium was collected and used for RNA extraction. For the collection of in planta samples, the strains were inoculated onto pre-wounded leaves as mentioned above. After incubation at $28{ }^{\circ} \mathrm{C}$ for $2 \mathrm{~d}$, the lesion area in the leaves were gathered and used for RNA extraction. The samples were disrupted in liquid nitrogen using a mortar with a pestle, and the RNA was extracted according to the manufacture's instruction by using the RNAprep Pure Plant Plus Kit (TIANGEN Biotech, Beijing, China). First strand cDNA was synthesized with FastKing gDNA Dispelling RT SuperMix (TIANGEN Biotech, Beijing, China). Then, a quantitative RT-PCR analysis was performed with ChamQ SYBR Color qPCR Master Mix (Vazyme, Nanjing, China) via the QuantStudio 6 (Thermo Fisher, Waltham, MA, USA). The primers named as gene-QF/gene-QR were used to perform the experiment (Supplementary Table S2). The $\beta 2$-tubulin coding gene was used as an endogenous control for normalization. All the reactions consisted of three biological replicates.

\subsection{Appressorium Formation Assay}

Polyester with a thickness of $25 \mu \mathrm{m}$ was placed on water agar; then aliquots of the conidia suspension were inoculated onto the polyester to induce the appressorium formation. After incubation at $28{ }^{\circ} \mathrm{C}$ for 8 and $18 \mathrm{~h}$, conidia germination behavior and appressorium formation were investigated under a microscope. At least 100 conidia were observed to calculate the appressorium formation rate. Each strain contained three biological replicates and the experiment was repeated twice.

\subsection{Melanin Content Measurement}

The melanin content was measured with the Fungal melanin quantification kit (GENMED SCIENTIFICS INC, Wilmington, DE, USA). Briefly, the conidia of the strains were inoculated into a liquid minimal medium supplemented with glutamine $\left(10 \mathrm{mmol} \mathrm{L}^{-1}\right)$ as nitrogen source with the initial concentration of $10^{4}$ conidia $\mathrm{mL}^{-1}$, and incubated at $160 \mathrm{rpm}, 28^{\circ} \mathrm{C}$ for $3 \mathrm{~d}$. The mycelium was collected and grounded to a fine powder in liquid nitrogen. Then, $0.1 \mathrm{~g}$ of the powder was used for melanin extraction according to the manufacture's protocol. After that, the melanin content was quantitated at $360 \mathrm{~nm}$ using a spectrophotometer (Eppendorf, Donau City, Germany). Both WT and the mutant contained three biological replicates.

\subsection{Chromatin Immunoprecipitation (ChIP) and Quantitative PCR Analysis}

ChIP analysis was performed according to our previous work with some modification [37]. The FLAG-tagged mutant strain was used for the ChIP assays. The protoplast was prepared and adjusted to the concentration of $10^{7}$ cell $\mathrm{mL}^{-1}$, with a total volume of $10 \mathrm{~mL}$. Genomic DNA and protein were cross-linked with $0.75 \%$ of formaldehyde for $10 \mathrm{~min}$ and the reaction was then stopped using $125 \mathrm{mmol} \mathrm{L}^{-1}$ glycine. Then, the sample was added with ChIP lysis buffer, and the nuclei were isolated by centrifugation at $4{ }^{\circ} \mathrm{C}$, $1000 \times g$ for $10 \mathrm{~min}$. After re-suspended with ChIP shearing buffer, the chromosome was sonicated for $5 \mathrm{~min}$, with the pulse of $8 \mathrm{~s}$ sonication and $5 \mathrm{~s}$ interval, to an average size of 200-500 bp via a Vibra-Cell Processors (Sonics, Newtown, CT, USA). A small aliquot of sonicated chromatin was used as the input DNA control. After that, the chromatin solution was immunoprecipitated using Anti-FLAG ${ }^{\circledR}$ M2 Magnetic Beads (Sigma-Aldrich, Louis, MA, USA) for $12 \mathrm{~h}$ at $4{ }^{\circ} \mathrm{C}$ with rotation; the sample incubated with IgG2a Magnetic Beads (MBL BEIJING BIOTECH, Beijing, China) was used as a mock/negative control. After the reverse of the cross-link and DNA purification, the enrichment of the promoter regions surrounding heat stress elements (HSEs) were determined by real-time quantitative PCR. 
Each sample contained three replicates and the experiment was conducted twice. The primers used are listed in Supplementary Table S2.

\subsection{Recombinant Protein Preparation and Electrophoretic Mobility Shift Assay (EMSA)}

EMSA analysis was performed as described by Ream et al. [38]. The coding sequence of Cghsf1 was amplified, digested with KpnI and HindIII, and cloned into the same sites of pCOLD vector. The recombinant vector was transformed into Escherichla coli strain BL21 (DE3). The expression of the recombinant proteins was induced by isopropyl $\beta$-D1-thiogalactopyranoside at $16{ }^{\circ} \mathrm{C}$ and purified with Ni-NTA Superflow (QIAGEN, Venlo, The Netherlands) according to the manufacturer's instructions. Oligonucleotide probes containing the HSE element were synthesized based on sequences of the target gene promoters. A total of $40 \mathrm{ng}$ of double-stranded probes and $10 \mathrm{mg}$ of protein were mixed in $50 \mu \mathrm{L}$ volume and incubated at $25^{\circ} \mathrm{C}$ for $2 \mathrm{~h}$. After incubation, the samples were loaded into $2 \%(w / v)$ agarose gel and electrophoresis was conducted using $0.5 \times \mathrm{TB}$ buffer at $10 \mathrm{~V} / \mathrm{cm}$. After staining with ethidium bromide (EB), the agarose gel was visualized using a GelDoc imager system (BIO-RAD, Hercules, CA, USA).

\subsection{Statistical Analysis}

Data with a single variable were analyzed by one-way ANOVA, and mean separations were performed by Duncan's multiple range test. Differences at $p<0.05$ were considered significant.

\section{Results}

\subsection{Identification and Bioinformatic Analysis of CgHSF1}

The HSF1 protein coding gene Cghsf1 was identified in the C. gloeosporioides genomic sequence. Cghsf1 contains a 2181 bp open reading frame separated by one intron, and it encodes the protein CgHSF1 of 727 amino acids (Supplementary Table S1). To investigate the similarity relationships of CgHSF1 between other fungal HSF1 proteins, an unrooted phylogenetic tree was constructed (Figure 1A). The phylogenetic analysis indicated that HSF1 proteins are highly conserved in plant pathogenic fungi, and CgHSF1 has a higher similarity to that of other Colletotrichum genus. Through searching against the Pfam database, CgHSF1 was found to contain a conserved HSF type DNA-binding domain at the 137-238 amino acids (Figure 1B).

\subsection{Subcellular Localization of CgHSF1}

To investigate the subcellular localization of CgHSF1, the CgHSF1-sGFP tagged strain was constructed (Figures 2A and S2). The strain expressing sGFP, which is driven by the promoter of glyceraldehyde-3-phosphate dehydrogenase gene from Aspergillus nidulans (PgpdA), was used as control check (CK). A thin layer of yeast casein sucrose (YCS) medium $\left(1 \mathrm{~g} \mathrm{~L}^{-1}\right.$ yeast extract, $1 \mathrm{~g} \mathrm{~L}^{-1}$ acid hydrolyzed casein, $2 \% w / v$ sucrose, $0.5 \% w / v$ agar, $\left.\mathrm{pH} 6.9\right)$ was plated into dimples of slides. Then, a conidia suspension in $\mathrm{ddH}_{2} \mathrm{O}$ was inoculated on the medium and the slides were kept in Petri dishes with lids at $28^{\circ} \mathrm{C}$ for $12-16 \mathrm{~h}$. After incubation, the slide was observed under a confocal. The results showed that the fluorescence of the $\mathrm{CK}$ was located in both the cell nucleus and cytoplasm, whereas that of CgHSF1-sGFP was mainly located in the cell nucleus, as evidenced by the co-localization of $4^{\prime}$,6-diamidino-2-phenylindole (DAPI) staining (Figure 2B).

\subsection{Generation of the PniiA-Cghsf1 Strain}

We firstly tried to construct the Cghsf1 knock-out mutant via a recombination strategy (Supplementary Figure S1), but the results of three round transformation attempts were unsuccessful; coupled with the previous reports [39], we concluded that Cghsf1 is essential for the viability of $C$. gloeosporioides. Therefore, we generated the mutant strain in which Cghsf1 was under the control of a repressive promoter PniiA (Figures 3A and S4). Three independent PCR diagnoses and sequencings verified that the two recombinant fragments 
were correctly integrated into the locus between "ATG" of Cghsf1 and its native promoter; and the expression cassette of PniiA-Cghsf1 was also correct in sequence (Figure 3B). After purification by a single conidia isolation, the mutant strain was named as PniiA-Cghsf1. After that, the transcription levels of Cghsf1 in the PniiA-Cghsf1 strain during in vitro and in planta stage were investigated. Through qRT-PCR, we found that the expression level of Cghsf1 in PniiA-Cghsf1 was about 4.27-fold lower than WT during in planta stage, whereas when cultured on medium in vitro, the transcripts of Cghsf1 in the mutant were 4.21-fold higher than that of WT (Figure 3C). These results suggested that in the mutant strain PniiA-Cghsf1, Cghsf1 was significantly repressed in planta.

A

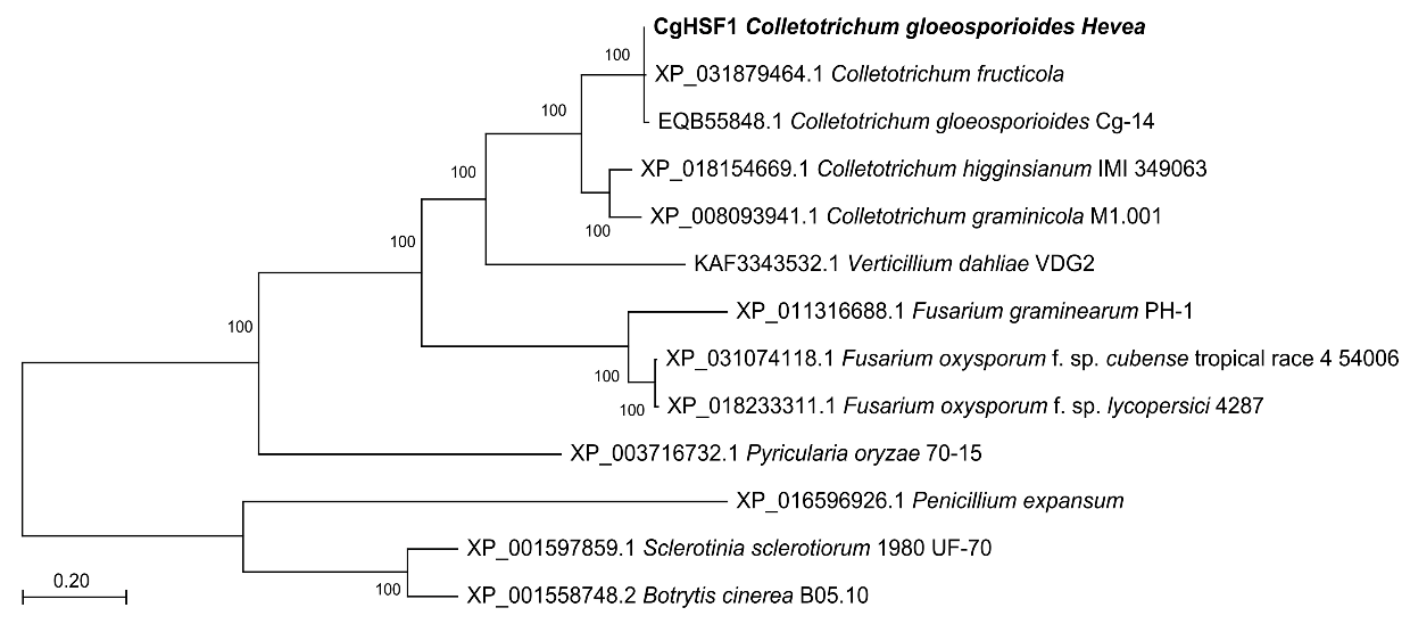

B

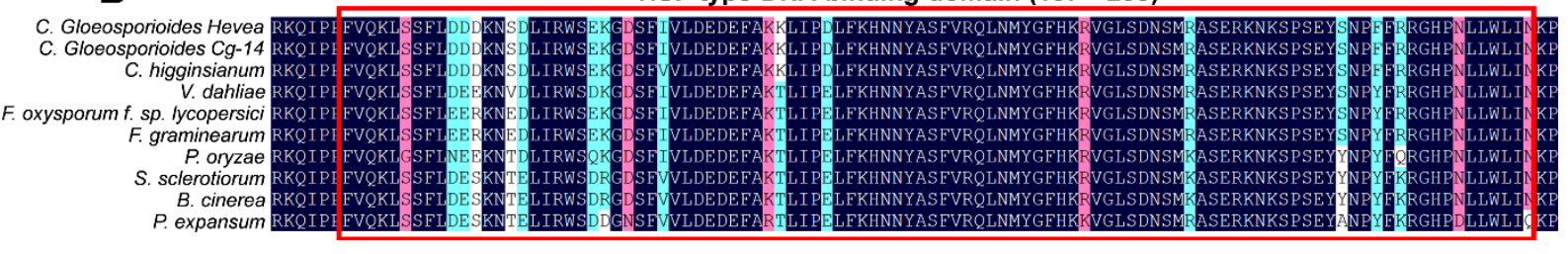

Figure 1. Bioinformatic analysis of CgHSF1. (A) The phylogenetic relationship of CgHSF1 and HSF1 proteins from some other plant pathogenic fungi. (B) Comparison of the conserved HSF DNA binding domain of fungal HSF1 proteins.

\section{A}

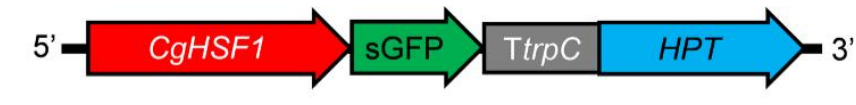

B
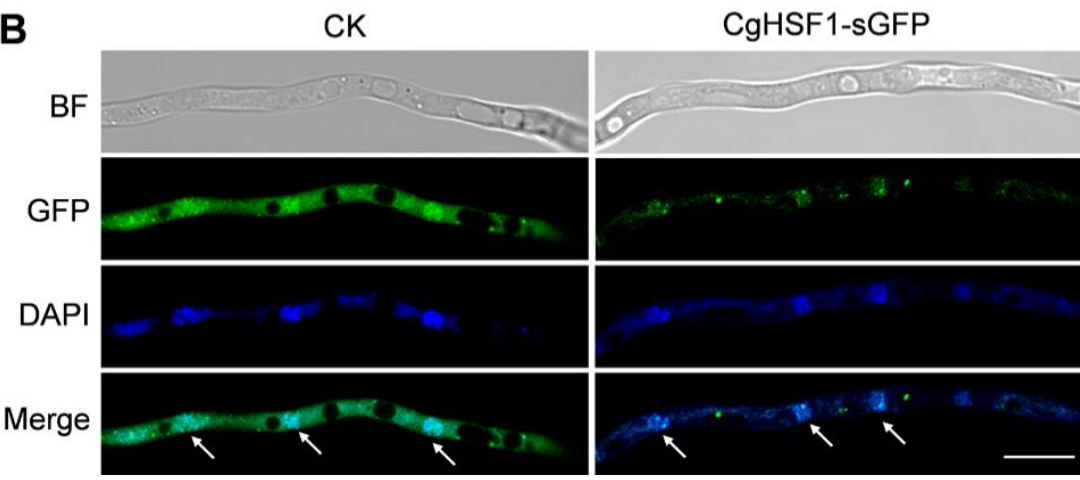

Figure 2. The subcellular localization of CgHSF1. (A) Expression cassette of CgHSF1-sGFP. (B) Fluorescence microscopes of hyphae. The arrowheads indicate nuclei. BF: bright field. DAPI: $4^{\prime}, 6$-diamidino-2-phenylindole. Scale Bar $=25 \mu \mathrm{m}$. 


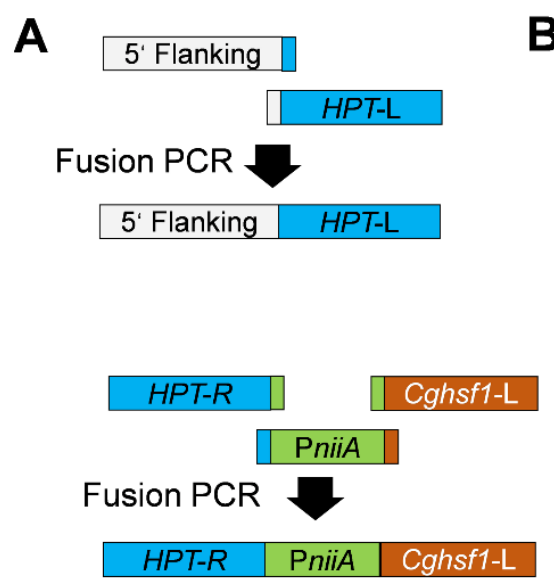

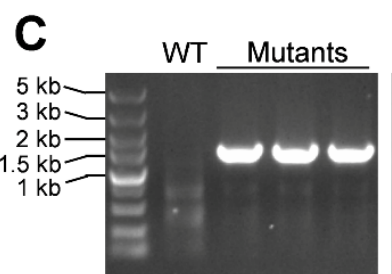

5 ' integration

(2) integration
B WT

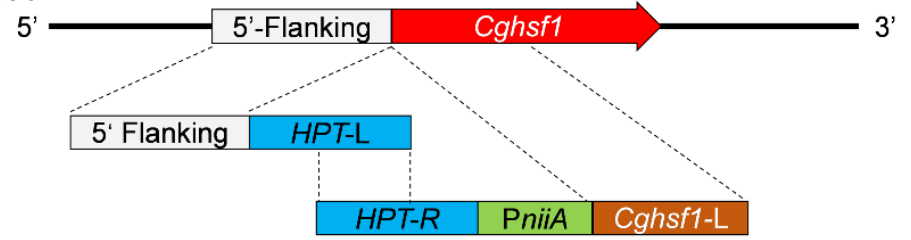

PniiA-Cghsf1

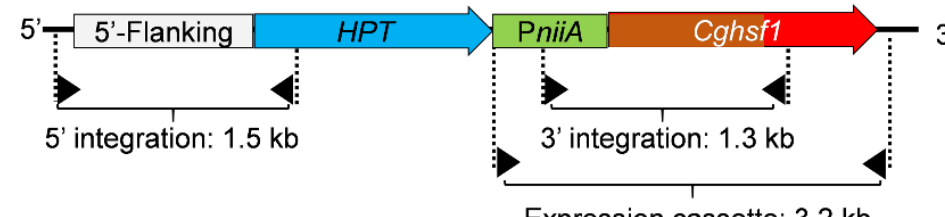

Expression cassette: $3.2 \mathrm{~kb}$

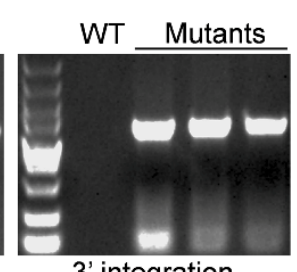

3' integration

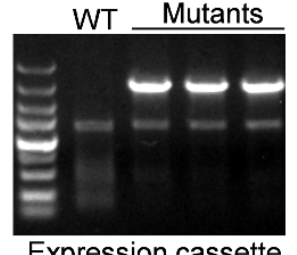

Expression cassette

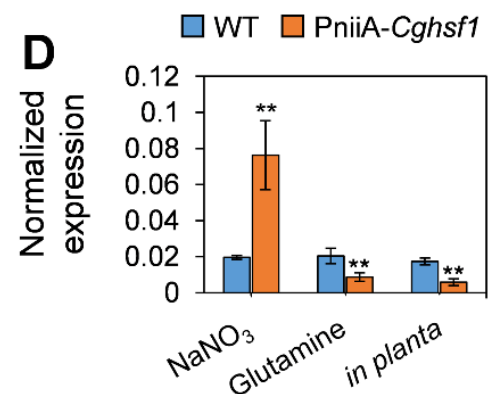

Figure 3. Construction of the repressive strain PniiA-Cghsf1. (A) Strategy for overlap PCR. The overlap nucleotides were indicated with the colors corresponding to relative fragments. Cghsf1-L indicate the nucleotides of $5^{\prime}$ part of Cghsf1 with about $800 \mathrm{bp}$. (B) Strategy for the construction of PniiA-Cghsf1 via recombination (C) Independent PCR diagnosis for the integration of the two recombinant fragments into the target locus, and diagnosis for correctness of the expression cassette. (D) Normalized expression level of Cghsf1 in WT and the mutant in response to nitrogen sources and during in planta stage. The $\beta 2$-tubulin coding gene was used as an endogenous control for normalization. Values are shown as the means \pm standard deviations (SD). Asterisks indicate significant difference at $p<0.01\left({ }^{* *}\right)$.

\subsection{CgHSF1 Is Required for Pathogenicity}

To analyze the role of CgHSF1 in the pathogenicity of C. gloeosporioides to Hevea, the conidia of the strains were inoculated on detached leaves with or without wounds. The results showed that WT strain caused typical anthracnose symptoms on the intact leaves with a disease incidence of $55 \%$, and the lesions were about $7 \mathrm{~mm}$ in diameter at $3 \mathrm{dpi}$; whereas the PniiA-Cghsf1 caused no lesions on the intact leaves (Figure 4A-C). When inoculated onto the pre-wounded leaves, both WT and PniiA-Cghsf1 successfully infected the leaves (Figure 4D,E); however, the lesion diameters caused by PniiA-Cghsf1 were merely $2 \mathrm{~mm}$, in comparison with that of $8 \mathrm{~mm}$ in WT (Figure 4F). These results suggested CgHSF1 is required for the pathogenicity of $C$. gloeosporioides through the regulation of both the initial infection process and the following hyphae development in host cells. 


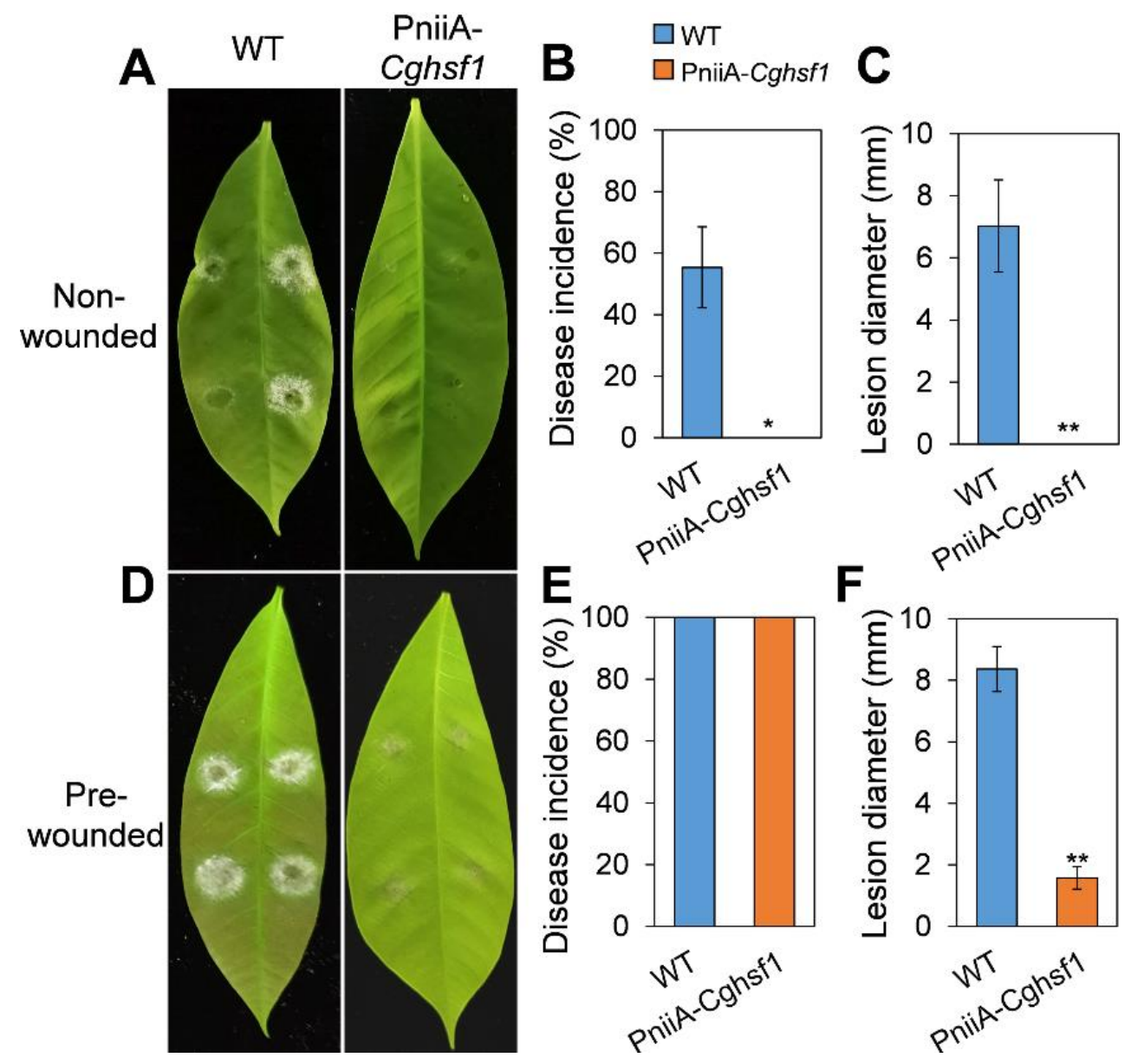

Figure 4. Pathogenicity assay of PniiA-Cghsf1. Figures and the data were captured at $3 \mathrm{~d}$ post inoculation. Disease symptoms of the intact rubber tree leaves (A) and pre-wounded leaves (D). Disease incidence of the intact rubber tree leaves (B) and pre-wounded leaves (E). Lesion diameters in the intact rubber tree leaves $(\mathbf{C})$ and pre-wounded leaves $(\mathbf{F})$. Values are shown as the means \pm standard deviations (SD) of three groups of samples. Asterisks indicate significant difference at $p<0.05\left(^{*}\right)$ and $\left.p<0.01{ }^{* *}\right)$.

\subsection{CgHSF1 Plays a Role in Appressorium Formation}

To investigate whether CgHSF1 is involved in appressorium formation, the conidia of PniiA-Cghsf1 was inoculated onto polyester and the germination behavior was analyzed. The results showed that WT and PniiA-Cghsf1 had similar germination rates after incubation for $8 \mathrm{~h}$ (Figure 5B). In addition, about 73\% of the WT conidia formed typical appressoria, together with the melanin deposition at the appressorium cell wall, whereas only $23 \%$ conidia of PniiA-Cghsf1 formed appressoria with abnormal shapes and longer germ tubes; furthermore, there is little melanin deposition in these abnormal appressoria. After incubation for another $10 \mathrm{~h}$, over $80 \%$ of the WT conidia formed appressoria with obvious melanism; in comparison, only $34 \%$ conidia of PniiA-Cghsf1 formed appressoria, most of which are with abnormal shapes (Figure 5A,C). 

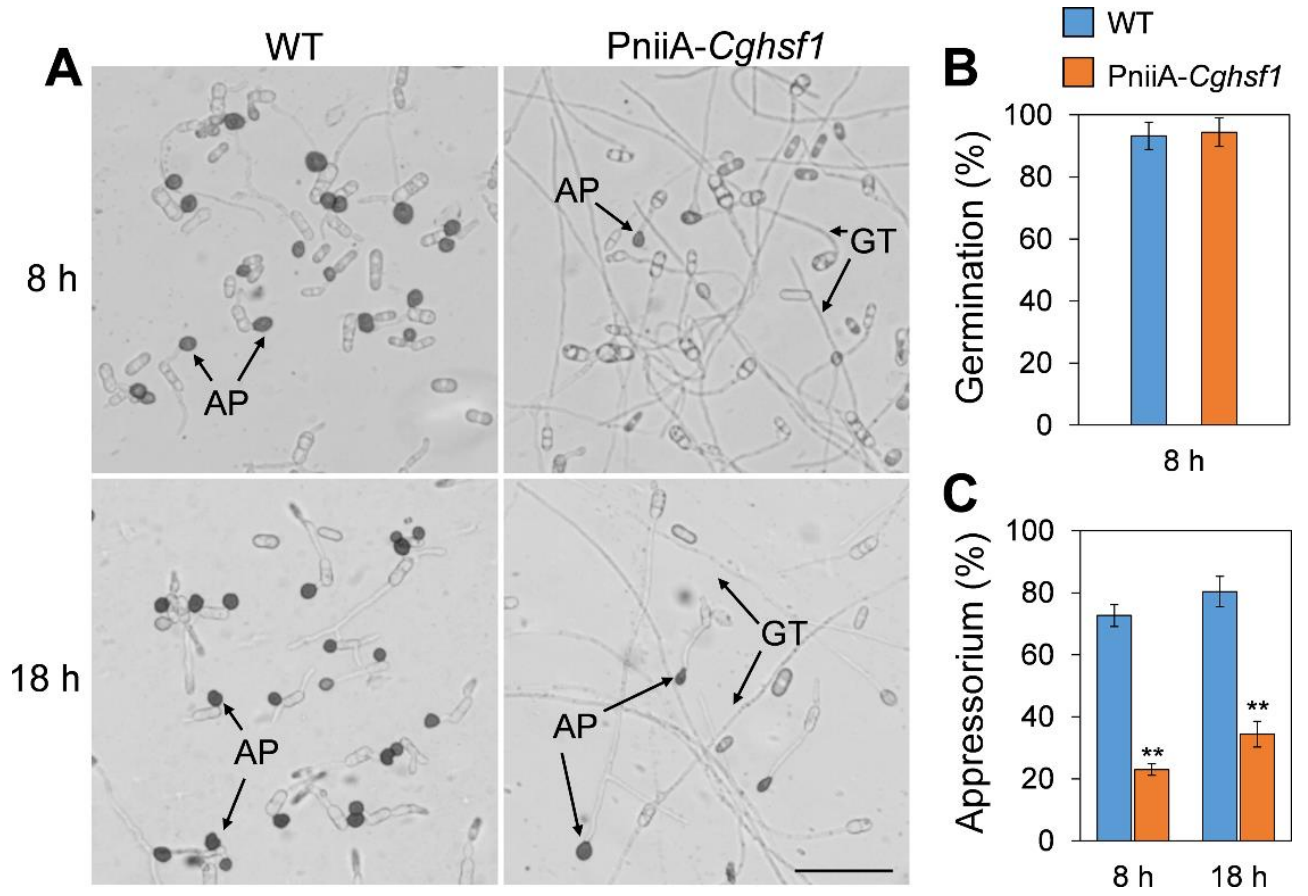

Figure 5. Conidia germination and appressorium formation analysis. (A) Microscopes of conidia after incubation on polyester for 8 and $18 \mathrm{~h}$. AP: appressoria. GT: germ tube. Bar $=50 \mu \mathrm{M}$. (B) Conidia germination rates of WT and PniiA-Cghsf1 strains. (C) Appressorium formation rates of WT and PniiA-Cghsf1 strains. Values are shown as the means \pm standard deviations (SD) of three groups of samples. Asterisks indicate significant difference at $p<0.01\left(^{* *}\right)$.

\subsection{CgHSF1 Plays a Role in Melanin Biosynthesis}

To investigate whether CgHSF1 plays a role in melanin biosynthesis, the melanin biosynthesis in the PniiA-Cghsf1 mutant was observed and measured. WT and PniiACghsf1 strains were cultured on solidified minimal medium supplemented with different nitrogen sources for $6 \mathrm{~d}$. The results (Figure 6A) showed that when cultured on the rich medium with yeast extract as the nitrogen source, WT and the PniiA-Cghsf1 mutant showed a higher growth rate than that cultured with the other nitrogen sources, and the colonies of the two strains were both with obvious melanism at 3 and $6 \mathrm{~d}$. When cultured on a medium with $\mathrm{NaNO}_{3}$ as the sole nitrogen source, the mutant showed a decrease in colony growth rate than WT (Figure 6B); besides, both WT and the mutant showed obvious melanism at $6 \mathrm{~d}$. When cultured on minimal medium with ammonium tartrate and glutamine, WT colonies showed a strong melanism at $3 \mathrm{~d}$; in comparison, those of the PniiA-Cghsf1 showed only a little melanism; in addition, after culture for another $3 \mathrm{~d}$, the PniiA-Cghsf1 mutant still produced obviously less melanin than WT on the medium with glutamine. Then, WT and the PniiA-Cghsf1 mutant strains were incubated in a liquid medium supplemented with glutamine, and the melanin content was quantitated. After incubation in the liquid medium for $3 \mathrm{~d}$, the mycelium of WT produced $485 \mu \mathrm{g}$ melanin per $\mathrm{g}$ of fresh mycelia, while that of PniiA-Cghsf1 was only 202 (Figure 6C). These results suggest that CgHSF1 plays a role in melanin biosynthesis. 

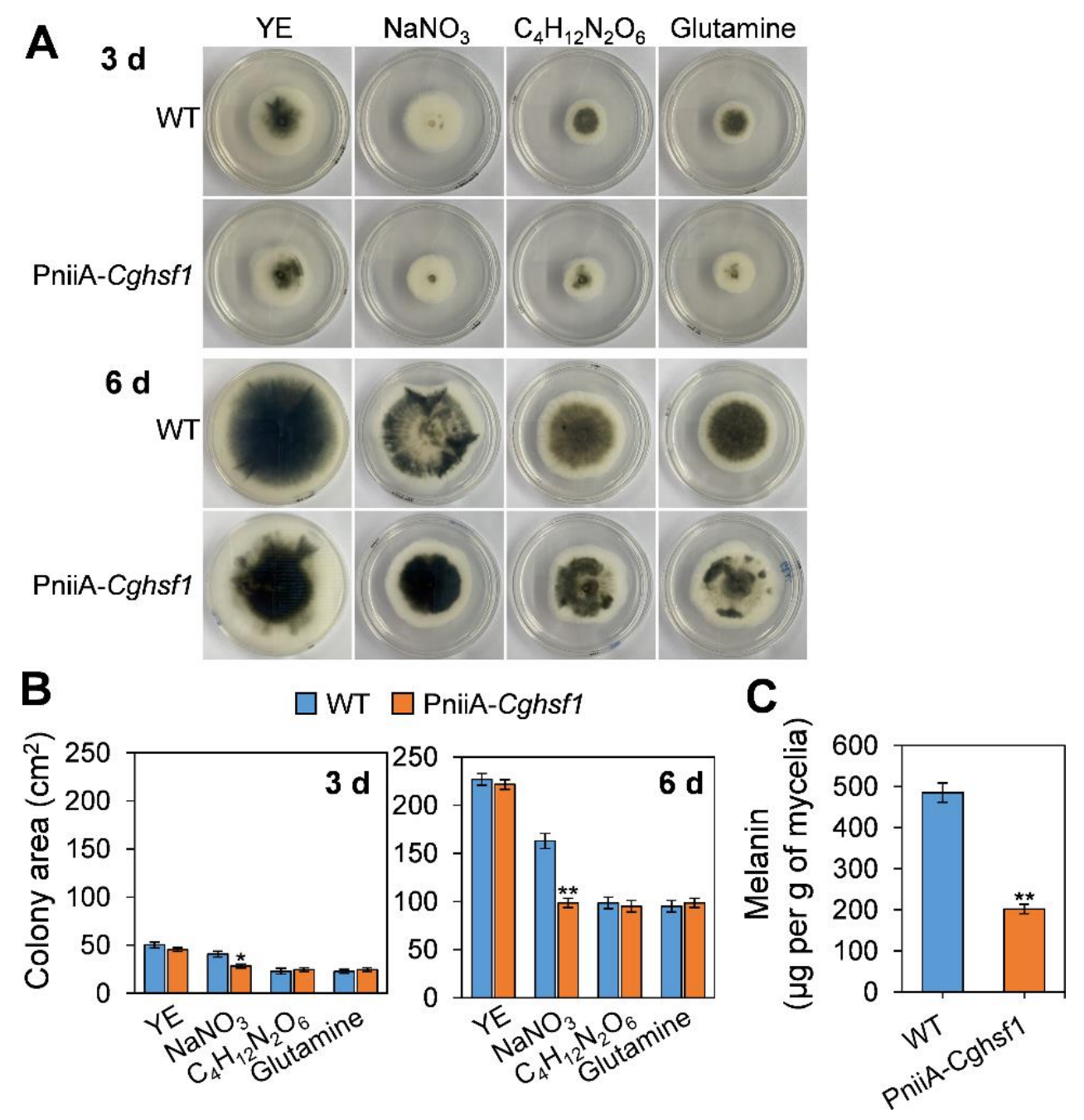

Figure 6. Growth analysis and measurement of melanin biosynthesis. (A) Colony morphology (bottom) of WT and the PniiA-Cghsf1 mutant after growth on minimal medium supplemented with yeast extract $\left(\mathrm{YE}, 2 \mathrm{~g} \mathrm{~L}^{-1}\right), \mathrm{NaNO}_{3}\left(20 \mathrm{mmol} \mathrm{L}^{-1}\right)$, ammonium tartrate $\left(\mathrm{C}_{4} \mathrm{H}_{12} \mathrm{~N}_{2} \mathrm{O}_{6}\right)\left(10 \mathrm{mmol} \mathrm{L}^{-1}\right)$, and glutamine $\left(10 \mathrm{mmol} \mathrm{L}^{-1}\right)$ as nitrogen sources. (B) Colony area after growth on minimal medium for 3 and $6 \mathrm{~d}$. (C) Quantitation of melanin after growth in a liquid minimal medium supplemented glutamine for $3 \mathrm{~d}$. Columns with asterisks indicate significant difference at $p<0.05\left(^{*}\right)$ and $p<0.01\left(^{* *}\right)$.

\subsection{CgHSF1 Regulates Transcription of Melanin Biosynthesis Genes}

There was a total of eight proteins involved in melanin biosynthesis being identified in C. gloeosporioides, including the transcription factor CMR1, polyketide synthase (PKS), polyketide shortening (YG), HN reductase (T4HRa and T4HRb), scytalone dehydratase (SCD), multicopper oxidase (T3HR), and laccase (Supplementary Table S2). To investigate whether CgHSF1 regulates the transcription of these melanin biosynthesis pathway genes, the qRT-PCR was conducted. The results showed that these genes except for T3HR were significantly down-regulated in both the appressoria and in planta hyphae of PniiA-Cghsf1 (Figure 7). 

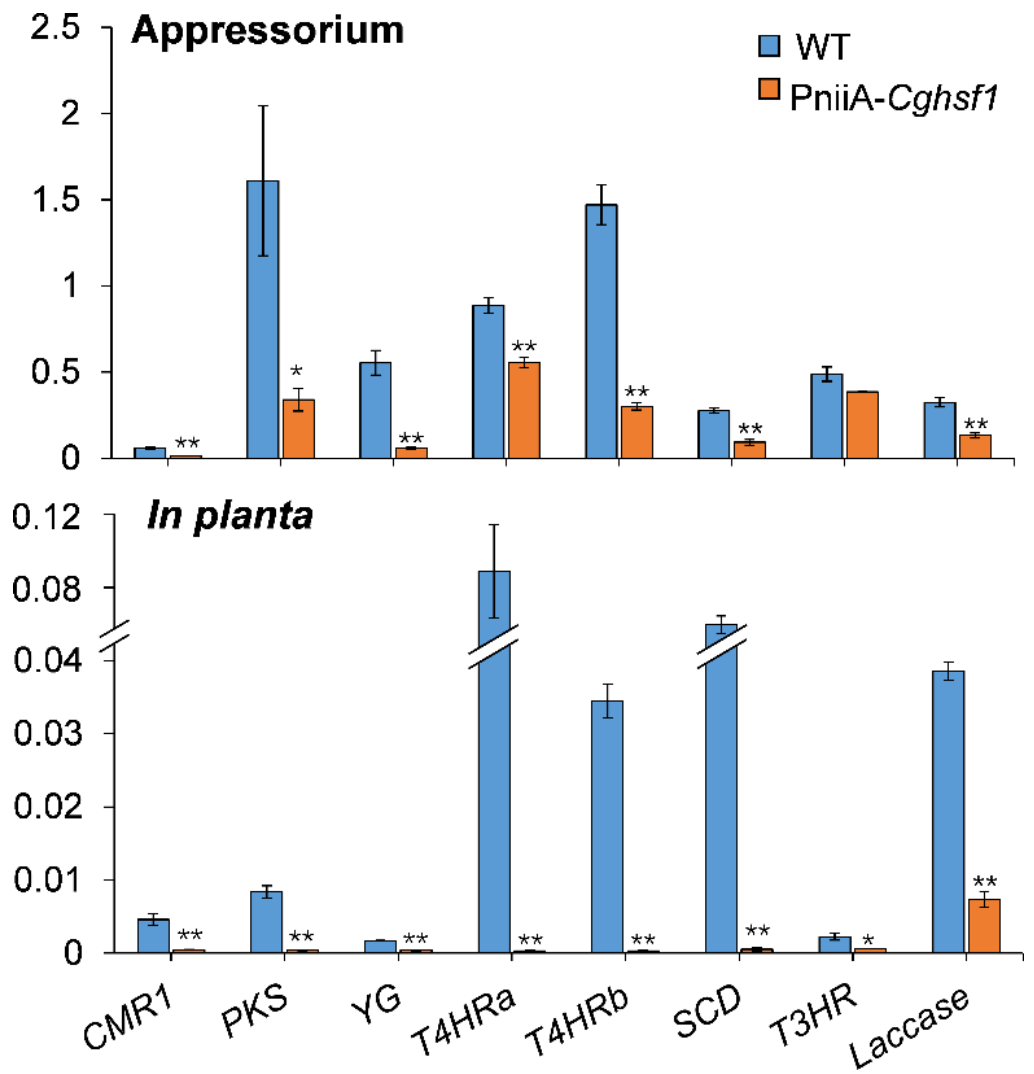

Figure 7. Normalized expression levels of melanin biosynthesis pathway genes in the appressoria and in planta stages of PniiA-Cghsf1. The $\beta 2$-tubulin coding gene was used as an endogenous control for normalization. Values are shown as the means \pm standard deviations (SD). Asterisks indicate significant difference at $p<0.05\left({ }^{*}\right)$ and $p<0.01\left({ }^{* *}\right)$.

\subsection{CgHSF1 Directly Binds to the Promoters of Melanin Biosynthesis Genes}

The presence of HSE (GAAnTTC and GAAnnTTC) elements was examined in the 2 $\mathrm{kb}$ upstream regions of these melanin biosynthetic genes. The in silicon analysis showed that seven of eight genes except PKS contain at least one HSE element in their promoters. Therefore, we performed a ChIP-qPCR using the CgHSF1-FLAG tagged strain. The chromatin pellet was immunoprecipitated using Anti-FLAG, and the enrichment of promoter fragments containing HSEs was expressed as the percentage relative to the input DNA. The results show an enrichment in the promoter regions of four genes, CMR1, YG, T4HRa, and $S C D$, compared with when nonspecific antibodies (IgG2a) were used (Figure 8). Additionally, the control experiment with the promoter region of $\beta 2$-tubulin showed that there is no non-specific enrichment for the sequences that do not contain HSE elements. Furthermore, the bindings of CgHSF1 to the corresponding probes containing HSEs of the four candidate genes were confirmed by the gel shift bands of the EMSA assay (Figure 9). Taken together with the gene expression analysis that revealed that the expression of melanin-related genes was lower in the mutant than in WT, these data suggest that CgHSF1 directly binds to the promoters and activates the transcription of these four melanin-biosynthesis-related genes. 


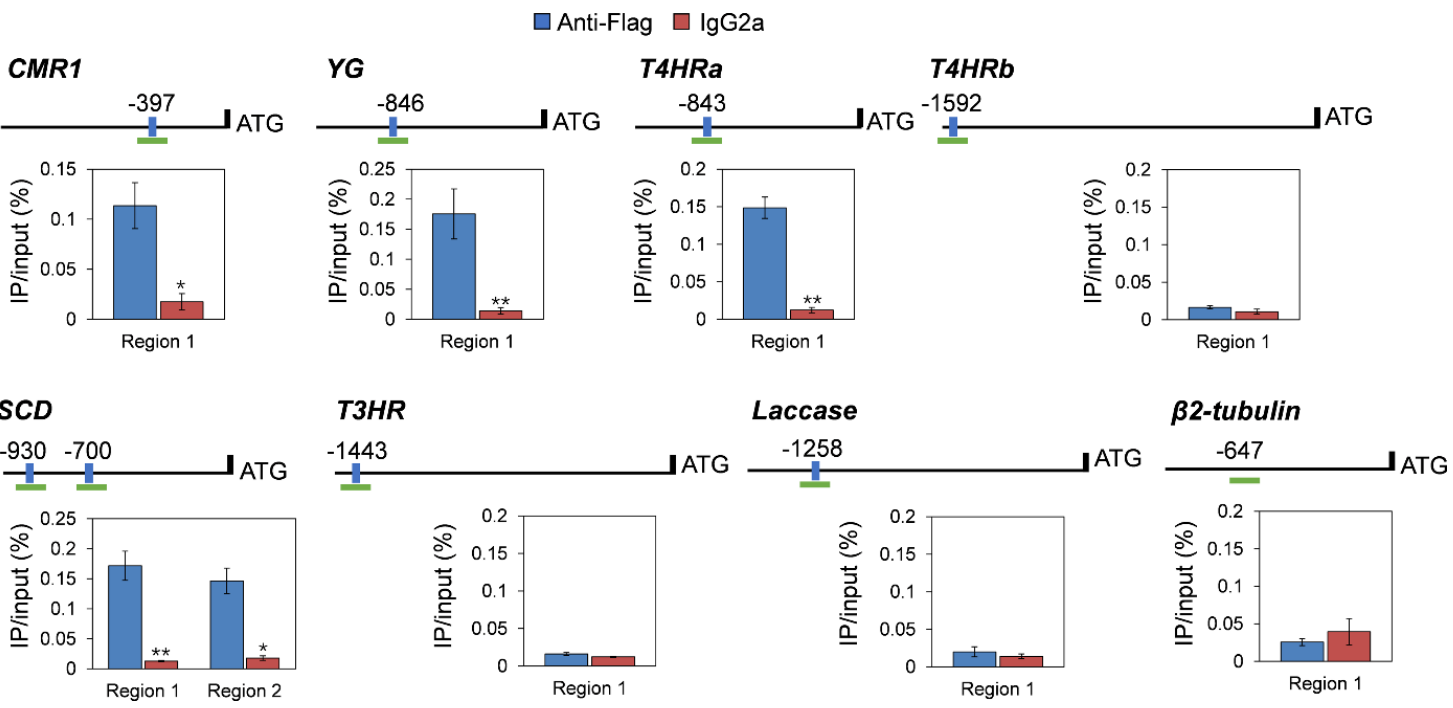

Figure 8. ChIP-qPCR assays indicated that CgHSF1 directly binds to the promoters of four melanin biosynthesis genes. The promoter structures are shown in the schematic diagrams. Blue boxes with numbers represent the positions of HSE elements to the translational start site. Green fragments represent the regions used for ChIP-qPCR. Values are the percentage of DNA fragments that were coimmunoprecipitated with specific anti-FLAG antibodies or non-specific antibodies relative to the input DNA. Error bars represent the standard deviations (SD) of three independent experiments. Asterisks indicate significant difference at $p<0.05\left(^{*}\right)$ and $p<0.01\left(^{* *}\right)$ between samples co-immunoprecipitated with anti-FLAG and IgG2a.
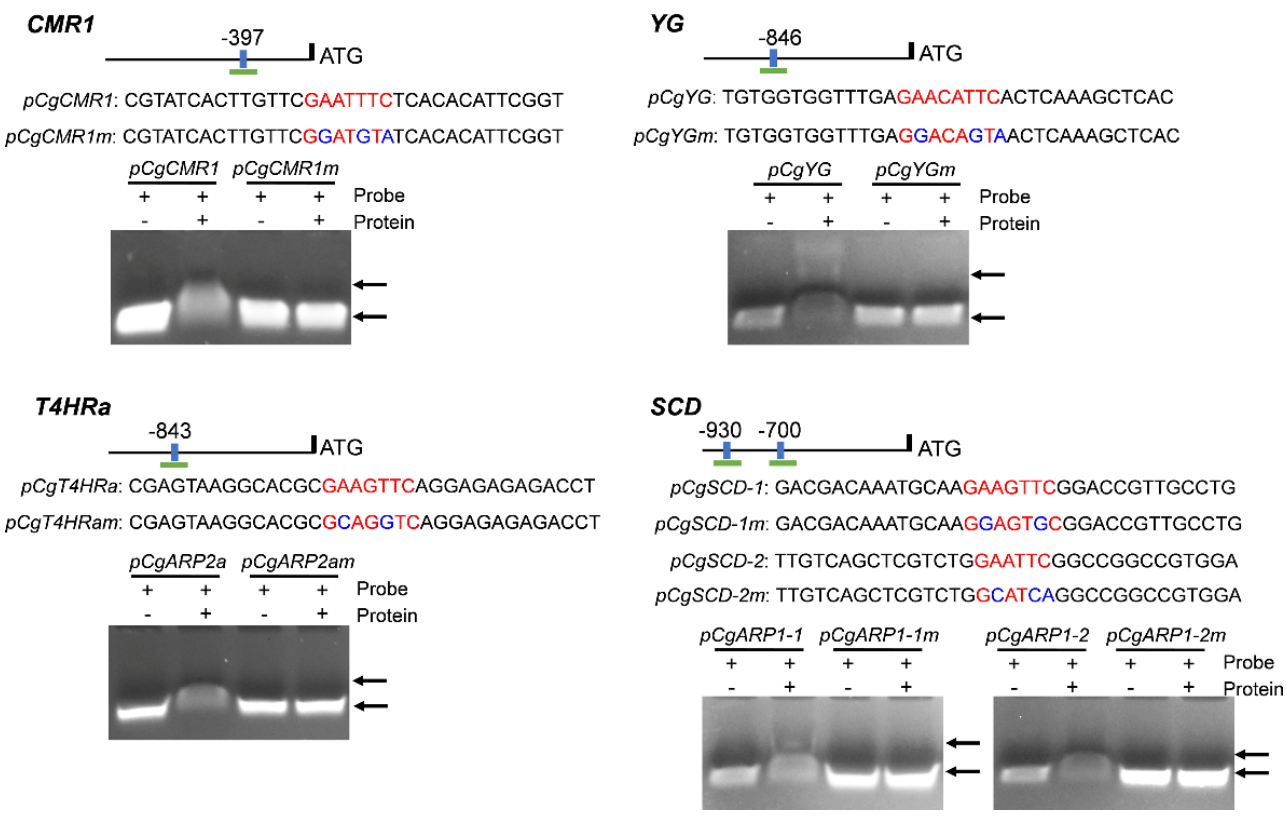

Figure 9. Gel mobility shift assays revealed that CgHSF1 directly binds to the HSE elements in the promoter region of four melanin biosynthesis genes. The native probe and mutated probe sequences corresponding to the promoters are shown, with red letters representing the HSE elements, and blue letters representing the mutated bases. Arrowheads indicate the specific complexes.

\section{Discussion}

Pathogenic fungi have evolved sophisticated mechanism to infect their hosts by producing virulence factors, including effectors, enzymes, and secondary metabolites. The expression of the related genes is under tight regulation to assure successful infection and 
colonization. Our goal was to determine if the HSF transcription factor modulates virulence in C. gloeosporioides. The phylogenetic analysis and protein domain analysis revealed that CgHSF1 is highly conserved in phytopathogenic fungi, and it contains a typical HSF-type DNA-binding domain. The microscopic analysis showed the specific subcellular location of CgHSF1 in the nucleus. These results confirmed that CgHSF1 is a transcription factor. To investigate its biological functions, we firstly tried to construct the Cghsf1 knock-out mutant. However, the failures of the attempts suggested that CgHSF1 is essential for the viability $C$. gloeosporioides. Similar results were also found in HSFs of $C$. albicans, which are required for core gene expression [39]. In many filamentous fungi, nitrite reductase (niiA) and nitrate reductase (niaD) genes were inducible by the presence of nitrate when cultured in vitro [40-42]. In this study, we found that the transcription of CgniiA was dramatically repressed when cultured with glutamine as the sole nitrogen source and during the in planta stage (Supplementary Figure S4). Therefore, the promoter of CgniiA (PniiA) was used to modulate the expression of Cghsf1, and the mutant PniiA-Cghsf1 was constructed by inserting the PniiA promoter between the coding sequence of Cghsf1 and its native promoter. The following qRT-PCR analysis showed that the expression level of Cghsf1 in PniiA-Cghsf1 was induced by $\mathrm{NaNO}_{3}$ and repressed by glutamine when cultured in vitro; moreover, the expression level of Cghsf1 was reduced about fourfold than that of WT during in planta colonization.

Then, the pathogenicity of PniiA-Cghsf1 was assayed to investigate the role of CgHSF1 in the infection process. Here, the Hevea leaves were inoculated in two ways, with one group of leaves being pre-wounded and the other non-wounded. When inoculated onto the wounds of leaves, PniiA-Cghsf1 could infect the leaves and formed typical anthracnose symptoms; however, the lesion diameter caused by the mutant was significantly smaller than that of WT. Microorganisms that colonize plants are continually challenged with plant defense responses, of which the oxidative burst, the rapid release of reactive oxygen species (ROS), is one of the earliest responses of plant hosts against pathogens at the invasion site $[43,44]$. In our previous work, rubber tree leaves were found to have a strong ROS burst after the infection of C. gloeosporioides [36]. Moreover, HSF1 and its downstream target HSP90 is well known to play a primary and global role in stress responses in eukaryotic organisms $[19,45]$. In the soybean stem and root rot pathogen Phytophthora sojae, PsHSF1 is critical for the pathogenicity of the pathogen by detoxifying the plant's oxidative burst [46]. Thus, we speculated that the attenuated pathogenicity of PniiA-Cghsf1 was mainly due to the decreased tolerance to oxidative stress. Meanwhile, when inoculated onto the intact leaves, PniiA-Cghsf1 caused no lesion at all, suggesting that the mutant lost ability to penetrate the leaves. Colletotrichum species breach the intact cuticles of plant hosts via the formation of the specialized structures called appressoria [3]. So, the appressorium formation of PniiA-Cghsf1 was surveyed. The results showed that depletion of Cghsf1 significantly decreased appressorium formation; moreover, PniiA-Cghsf1 only formed appressoria with abnormal shapes and relative long germ tubes, and there is little melanin deposition in these abnormal appressoria. A series of proteins are already known for being involved in appressorium formation in pathogenic fungi, including cell cycle control regulators [47], autophagy components [48], MAP kinase pathway and the cAMP response pathway [49-51]. In the human pathogen C. albicans, HSF1 is required for virulence via controlling cell transition from yeast to filamentous growth [34]. These results enlightened us that CgHSF1 might control the cell developmental transition from germ tube to appressorium via interaction with these pathways, although there are different mechanisms in pathogenicity between C. albicans and plant pathogenic fungi.

It is interesting that melanin deposition was significantly impaired in the abnormal appressoria of PniiA-Cghsf1. There are two well-characterized pathways for melanin biosynthesis, the DOPA pathway and the DHN pathway [52,53]; and most of plant pathogenic fungi synthesize melanin via the DHN pathway. Melanin is well known for its biological function in the detoxification of ROS and protection against environmental stresses in living cells. In plant pathogenic fungi, melanin plays a myriad of biological roles in morphogen- 
esis, virulence, and energy transduction $[54,55]$. To investigate whether the depletion of Cghsf1 impairs melanin biosynthesis, the PniiA-Cghsf1 mutant was cultured on a solidified or in liquid minimal medium supplemented with different nitrogen sources. The colony growth analysis showed that induction or repression of transcription of Cghsf1 did not impair the vegetative growth, but significantly influenced the melanism in the PniiA-Cghsf1 mutant. When the expression of Cghsf1 was induced by nitrate, the colony melanism was observational increased in the mutant compared with WT, while when Cghsf1 was repressed by glutamine, the colony melanism was significantly reduced in the mutant, which was in accordance with the melanin quantitation results. Notably, the melanization of appressoria is indispensable for the successful infection of intact leaves, for it is required for development of high pressures within appressoria [56] and/or cell-wall rigidity in appressoria of the corn pathogen [57]. Then, the effect of CgHSF1 on the transcription of melanin biosynthesis enzymes was analyzed via a qRT-PCR analysis. The results showed that in the PniiA-Cghsf1 mutant, transcripts of six of seven melanin biosynthesis genes were significantly reduced in the appressoria, and all seven genes were reduced in the in planta tissues.

In fungi, the genes involved in secondary metabolite biosynthesis are frequently physically linked in the genome, which are named as clusters; in addition, expression of these gene clusters depends on specialized TFs [58]. Here, we found that transcription of the TF CMR1, the transcriptional activators of melanin biosynthesis [59,60], was downregulated in PniiA-Cghsf1. Although HSF proteins display a wide variability between different species, the heat shock element (HSE) that targeted by HSFs are well conserved. The HSE consists of three contiguous repeats of the short sequence 5'-nGAAn-3' [61]. The examination of the promoter regions of these seven melanin biosynthesis genes and CMR1 showed that CMR1, YG, T4HRa, and SCD, contained at least one HSE element (Supplementary Table S1). The following ChIP-PCR and EMSA analysis confirmed that the four genes were direct targets of CgHSF1. Although the other four genes, $P K S, T 4 H R b$, T3HR, and Laccase were not identified as the direct targets of CgHSF1, their transcriptions were also under the regulation of CgHSF1. We speculated that it is because that these four genes are the direct targets of CMR1 [52,53], and CgHSF1 could regulate their transcription in an indirect way. These findings revealed that, in addition to CMR1, CgHSF1 may also function as transcriptional activators of melanin biosynthesis.

Taken together, we conclude that CgHSF1 is involved in the pathogenicity of $C$. gloeosporioides through the activation of melanin biosynthesis genes and the regulation of appressorium formation (Figure 10). Our study extends the understanding of fungal HSF1 proteins, especially their involvement in pathogenicity.

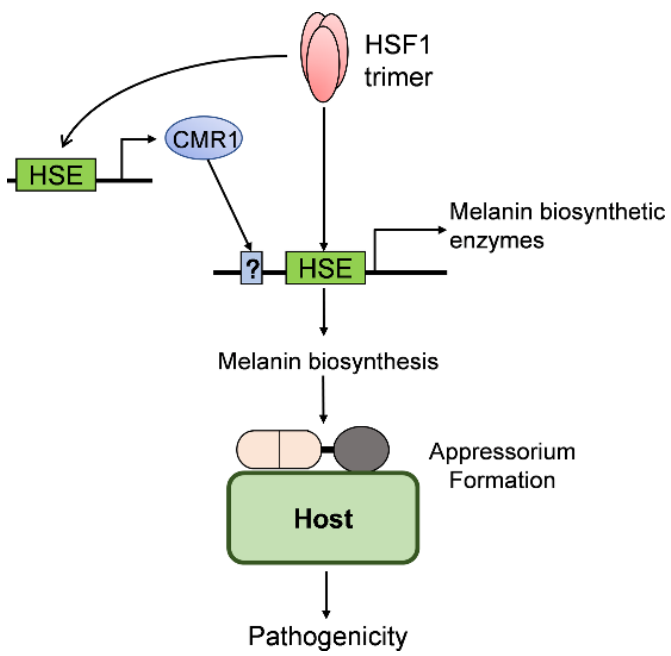

Figure 10. The proposed model of the CgHSF1 in the regulation of the pathogenicity of C. gloeosporioides. HSE: heat shock element. 
Supplementary Materials: The following are available online at https:/ /www.mdpi.com/article/10 .3390/jof8020175/s1. Figure S1: Split-Marker Strategy for construction of Cghsf1 knock-out mutants; Figure S2: Strategy for construction of CgHSF1-sGFP mutant; Figure S3: Strategy for the construction of CgHSF1-FLAG mutant; Figure S4: Normalized expression levels of CgniiA, CgniaD and Cghsf1 in WT strain cultured with different medium in vitro and during the in planta stage; Table S1: Nucleotide sequence of Cghsf1 and amino acid sequence of CgHSF1; Table S2: Proteins involved in melanin biosynthesis; Table S3: Primers used in the present study.

Author Contributions: Conceptualization, B.A.; investigation, X.G., Q.W., Q.F. and B.Z.; writingoriginal draft preparation, B.A., X.G. and Q.W.; writing-review and editing, H.L.; supervision, C.H.; funding acquisition, B.A. and Q.W. All authors have read and agreed to the published version of the manuscript.

Funding: This research was funded by the Natural Science Foundation of Hainan Province, 320RC479, and the National Natural Science Foundation of China, 32000102, 32001846, 32160594.

Institutional Review Board Statement: Not applicable.

Informed Consent Statement: Not applicable.

Conflicts of Interest: The authors declare no conflict of interest. The funders had no role in the design of the study; in the collection, analyses, or interpretation of data; in the writing of the manuscript, or in the decision to publish the results.

\section{References}

1. Dean, R.; Van Kan, J.A.; Pretorius, Z.A.; Hammond-Kosack, K.E.; Di Pietro, A.; Spanu, P.D.; Rudd, J.J.; Dickman, M.; Kahmann, R.; Ellis, J.; et al. The Top 10 Fungal Pathogens in Molecular Plant Pathology. Mol. Plant Pathol. 2012, 13, 414-430. [CrossRef] [PubMed]

2. Phoulivong, S.; Cai, L.; Chen, H.; McKenzie, E.H.; Abdelsalam, K.; Chukeatirote, E.; Hyde, K.D. Colletotrichum gloeosporioides Is Not a Common Pathogen on Tropical Fruits. Fungal Divers. 2010, 44, 33-43. [CrossRef]

3. O'Connell, R.J.; Thon, M.R.; Hacquard, S.; Amyotte, S.G.; Kleemann, J.; Torres, M.F.; Damm, U.; Buiate, E.A.; Epstein, L.; Alkan, N.; et al. Lifestyle Transitions in Plant Pathogenic Colletotrichum Fungi Deciphered by Genome and Transcriptome Analyses. Nat. Genet. 2012, 44, 1060-1065. [CrossRef] [PubMed]

4. Gan, P.; Ikeda, K.; Irieda, H.; Narusaka, M.; O'Connell, R.J.; Narusaka, Y.; Takano, Y.; Kubo, Y.; Shirasu, K. Comparative Genomic and Transcriptomic Analyses Reveal the Hemibiotrophic Stage Shift of Colletotrichum Fungi. New Phytol. 2013, 197, 1236-1249. [CrossRef]

5. Huang, G.; Wang, H.; Chou, S.; Nie, X.; Chen, J.; Liu, H. Bistable Expression of WOR1, a Master Regulator of White-Opaque Switching in Candida albicans. Proc. Natl. Acad. Sci. USA 2006, 103, 12813-12818. [CrossRef]

6. Cain, C.W.; Lohse, M.B.; Homann, O.R.; Sil, A.; Johnson, A.D. A Conserved Transcriptional Regulator Governs Fungal Morphology in Widely Diverged Species. Genetics 2012, 190, 511-521. [CrossRef]

7. Jonkers, W.; Dong, Y.; Broz, K.; Kistler, H.C. The Wor1-Like Protein Fgp1 Regulates Pathogenicity, Toxin Synthesis and Reproduction in the Phytopathogenic Fungus Fusarium graminearum. PLoS Pathog. 2012, 8, e1002724. [CrossRef]

8. Brown, D.W.; Busman, M.; Proctor, R.H. Fusarium verticillioides SGE1 Is Required for Full Virulence and Regulates Expression of Protein Effector and Secondary Metabolite Biosynthetic Genes. Mol. Plant Microbe Interact. 2014, 27, 809-823. [CrossRef]

9. Michielse, C.B.; Studt, L.; Janevska, S.; Sieber, C.M.; Arndt, B.; Espino, J.J.; Humpf, H.U.; Güldener, U.; Tudzynski, B. The Global Regulator FfSge1 Is Required for Expression of Secondary Metabolite Gene Clusters but Not for Pathogenicity in Fusarium fujikuroi. Environ. Microbiol. 2015, 17, 2690-2708. [CrossRef]

10. Van der Does, H.C.; Fokkens, L.; Yang, A.; Schmidt, S.M.; Langereis, L.; Lukasiewicz, J.M.; Hughes, T.R.; Rep, M. Transcription Factors Encoded on Core and Accessory Chromosomes of Fusarium oxysporum Induce Expression of Effector Genes. PLoS Genet. 2016, 12, e1006401. [CrossRef]

11. Michielse, C.B.; van Wijk, R.; Reijnen, L.; Manders, E.M.; Boas, S.; Olivain, C.; Alabouvette, C.; Rep, M. The Nuclear Protein Sge1 of Fusarium oxysporum Is Required for Parasitic Growth. PLoS Pathog. 2009, 5, e1000637. [CrossRef]

12. Michielse, C.B.; Becker, M.; Heller, J.; Moraga, J.; Collado, I.G.; Tudzynski, P. The Botrytis cinerea Reg1 Protein, a Putative Transcriptional Regulator, Is Required for Pathogenicity, Conidiogenesis, and the Production of Secondary Metabolites. Mol. Plant Microbe Interact. 2011, 24, 1074-1085. [CrossRef]

13. Santhanam, P.; Thomma, B.P. Verticillium dahliae Sge1 Differentially Regulates Expression of Candidate Effector Genes. Mol. Plant Microbe Interact. 2013, 26, 249-256. [CrossRef]

14. Mirzadi Gohari, A.; Mehrabi, R.; Robert, O.; Ince, I.A.; Boeren, S.; Schuster, M.; Steinberg, G.; de Wit, P.J.; Kema, G.H. Molecular characterization and functional analyses of ZtWor1, a transcriptional regulator of the fungal wheat pathogen Zymoseptoria tritici. Mol. Plant Pathol. 2014, 15, 394-405. [CrossRef] 
15. Tollot, M.; Assmann, D.; Becker, C.; Altmüller, J.; Dutheil, J.Y.; Wegner, C.E.; Kahmann, R. The WOPR Protein Ros1 Is a Master Regulator of Sporogenesis and Late Effector Gene Expression in the Maize Pathogen Ustilago maydis. PLoS Pathog. 2016, 12, e1005697. [CrossRef]

16. Chen, Y.; Zhai, S.; Zhang, H.; Zuo, R.; Wang, J.; Guo, M.; Zheng, X.; Wang, P.; Zhang, Z. Shared and Distinct Functions of Two Gti1/Pac2 Family Proteins in Growth, Morphogenesis and Pathogenicity of Magnaporthe oryzae. Environ. Microbiol. 2014, 16, 788-801. [CrossRef]

17. Zahiri, A.; Heimel, K.; Wahl, R.; Rath, M.; Kämper, J. The Ustilago maydis Forkhead Transcription Factor Fox1 Is Involved in the Regulation of Genes Required for the Attenuation of Plant Defenses during Pathogenic Development. Mol. Plant Microbe Interact. 2010, 23, 1118-1129. [CrossRef]

18. Zheng, Y.; Kief, J.; Auffarth, K.; Farfsing, J.W.; Mahlert, M.; Nieto, F.; Basse, C.W. The Ustilago maydis Cys2His2-Type Zinc Finger Transcription Factor Mzr1 Regulates Fungal Gene Expression during the Biotrophic Growth stage. Mol. Microbiol. 2008, 68, 1450-1470. [CrossRef]

19. Akerfelt, M.; Morimoto, R.I.; Sistonen, L. Heat Shock Factors: Integrators of Cell Stress, Development and Lifespan. Nat. Rev. Mol. Cell Biol. 2010, 11, 545-555. [CrossRef]

20. Anckar, J.; Sistonen, L. Regulation of HSF1 Function in the Heat Stress Response: Implications in Aging and Disease. Annu. Rev. Biochem. 2011, 80, 1089-1115. [CrossRef]

21. Parker, C.S.; Topol, J. A Drosophila RNA Polymerase II Transcription Factor Binds to the Regulatory Site of an hsp 70 Gene. Cell 1984, 37, 273-283. [CrossRef]

22. Wiederrecht, G.; Shuey, D.J.; Kibbe, W.A.; Parker, C.S. The Saccharomyces and Drosophila Heat Shock Transcription Factors Are Identical in Size and DNA Binding Properties. Cell 1987, 48, 507-515. [CrossRef]

23. Gomez-Pastor, R.; Burchfiel, E.T.; Thiele, D.J. Regulation of Heat Shock Transcription Factors and Their Roles in Physiology and Disease. Nat. Rev. Mol. Cell Biol. 2018, 19, 4-19. [CrossRef]

24. Nover, L.; Bharti, K.; Döring, P.; Mishra, S.K.; Ganguli, A.; Scharf, K.D. Arabidopsis and the Heat Stress Transcription Factor World: How Many Heat Stress Transcription Factors Do We Need? Cell Stress Chaperones 2001, 6, 177-189. [CrossRef]

25. Jedlicka, P.; Mortin, M.A.; Wu, C. Multiple Functions of Drosophila Heat Shock Transcription Factor In Vivo. EMBO J. 1997, 16, 2452-2462. [CrossRef]

26. Shopland, L.S.; Hirayoshi, K.; Fernandes, M.; Lis, J.T. HSF Access to Heat Shock Elements In Vivo Depends Critically on Promoter Architecture Defined by GAGA Factor, TFIID, and RNA Polymerase II Binding Sites. Genes Dev. 1995, 9, 2756-2769. [CrossRef]

27. Moye-Rowley, W.S. Regulation of the Transcriptional Response to Oxidative Stress in Fungi: Similarities and Differences. Eukaryot. Cell 2003, 2, 381-389. [CrossRef]

28. Yan, L.J.; Christians, E.S.; Liu, L.; Xiao, X.; Sohal, R.S.; Benjamin, I.J. Mouse Heat Shock Transcription Factor 1 Deficiency Alters Cardiac Redox Homeostasis and Increases Mitochondrial Oxidative Damage. EMBO. J. 2002, 21, 5164-5172. [CrossRef]

29. Von Koskull-Döring, P.; Scharf, K.D.; Nover, L. The Diversity of Plant Heat Stress Transcription Factors. Trends Plant Sci. 2007, 12, 452-457. [CrossRef]

30. Guo, M.; Liu, J.H.; Ma, X.; Luo, D.X.; Gong, Z.H.; Lu, M.H. The Plant Heat Stress Transcription Factors (HSFs): Structure, Regulation, and Function in Response to Abiotic Stresses. Front. Plant Sci. 2016, 7, 114. [CrossRef]

31. Akerfelt, M.; Trouillet, D.; Mezger, V.; Sistonen, L. Heat Shock Factors at a Crossroad between Stress and Development. Ann. N. Y. Acad. Sci. 2007, 1113, 15-27. [CrossRef] [PubMed]

32. Wunderlich, M.; Gross-Hardt, R.; Schöffl, F. Heat Shock Factor HSFB2a Involved in Gametophyte Development of Arabidopsis thaliana and Its Expression is Controlled by a Heat-Inducible Long Non-Coding Antisense RNA. Plant Mol. Biol. 2014, 85, 541-550. [CrossRef] [PubMed]

33. Fujimoto, M.; Oshima, K.; Shinkawa, T.; Wang, B.B.; Inouye, S.; Hayashida, N.; Takii, R.; Nakai, A. Analysis of HSF4 Binding Regions Reveals Its Necessity for Gene Regulation during Development and Heat Shock Response in Mouse Lenses. J. Biol. Chem. 2008, 283, 29961-29970. [CrossRef] [PubMed]

34. Veri, A.O.; Miao, Z.; Shapiro, R.S.; Tebbji, F.; O'Meara, T.R.; Kim, S.H.; Colazo, J.; Tan, K.; Vyas, V.K.; Whiteway, M.; et al. Tuning Hsf1 Levels Drives Distinct Fungal Morphogenetic Programs with Depletion Impairing Hsp90 Function and Overexpression Expanding the Target Space. PLoS Genet. 2018, 14, e1007270. [CrossRef]

35. Tamura, K.; Stecher, G.; Kumar, S. MEGA11: Molecular Evolutionary Genetics Analysis Version 11. Mol. Biol. Evol. 2021, 38 , 3022-3027. [CrossRef]

36. Wang, Q.; An, B.; Hou, X.; Guo, Y.; Luo, H.; He, C. Dicer-Like Proteins Regulate the Growth, Conidiation, and Pathogenicity of Colletotrichum gloeosporioides from Hevea brasiliensis. Front. Microbiol. 2018, 8, 2621. [CrossRef]

37. Yang, J.; Wang, Q.; Luo, H.; He, C.; An, B. HbWRKY40 Plays an Important Role in the Regulation of Pathogen Resistance in Hevea brasiliensis. Plant Cell Rep. 2020, 39, 1095-1107. [CrossRef]

38. Ream, J.A.; Lewis, L.K.; Lewis, K.A. Rapid Agarose Gel Electrophoretic Mobility Shift Assay for Quantitating Protein: RNA Interactions. Anal. Biochem. 2016, 511, 36-41. [CrossRef]

39. Nicholls, S.; Leach, M.D.; Priest, C.L.; Brown, A.J. Role of the Heat Shock Transcription Factor, Hsf1, in a Major Fungal Pathogen That Is Obligately Associated with Warm-Blooded Animals. Mol. Microbiol. 2009, 74, 844-861. [CrossRef]

40. Hu, W.; Sillaots, S.; Lemieux, S.; Davison, J.; Kauffman, S.; Breton, A.; Linteau, A.; Xin, C.; Bowman, J.; Becker, J.; et al. Essential Gene Identification and Drug Target Prioritization in Aspergillus fumigatus. PLoS Pathog. 2007, 3, e24. [CrossRef] 
41. Pinchai, N.; Perfect, B.Z.; Juvvadi, P.R.; Fortwendel, J.R.; Cramer, R.A.; Asfaw, Y.G.; Heitman, J.; Perfect, J.R.; Steinbach, W.J. Aspergillus fumigatus Calcipressin CbpA Is Involved in Hyphal Growth and Calcium Homeostasis. Eukaryot. Cell 2009, 8, 511-519. [CrossRef]

42. Lamoth, F.; Juvvadi, P.R.; Fortwendel, J.R.; Steinbach, W.J. Heat Shock Protein 90 Is Required for Conidiation and Cell Wall Integrity in Aspergillus fumigatus. Eukaryot. Cell 2012, 11, 1324-1332. [CrossRef]

43. Apostol, I.; Heinstein, P.F.; Low, P.S. Rapid Stimulation of an Oxidative Burst during Elicitation of Cultured Plant Cells: Role in Defense and Signal Transduction. Plant Physiol. 1989, 90, 109-116. [CrossRef]

44. Apel, K.; Hirt, H. Reactive Oxygen Species: Metabolism, Oxidative Stress, and Signal Transduction. Annu. Rev. Plant Biol. 2004, 55, 373-399. [CrossRef]

45. Leach, M.D.; Farrer, R.A.; Tan, K.; Miao, Z.; Walker, L.A.; Cuomo, C.A.; Wheeler, R.T.; Brown, A.J.; Wong, K.H.; Cowen, L.E. Hsf1 and Hsp90 Orchestrate Temperature-Dependent Global Transcriptional Remodelling and Chromatin Architecture in Candida albicans. Nat. Commun. 2016, 7, 11704. [CrossRef]

46. Sheng, Y.; Wang, Y.; Meijer, H.J.; Yang, X.; Hua, C.; Ye, W.; Tao, K.; Liu, X.; Govers, F.; Wang, Y. The Heat Shock Transcription Factor PsHSF1 of Phytophthora sojae Is Required for Oxidative Stress Tolerance and Detoxifying the Plant Oxidative Burst. Environ. Microbiol. 2015, 17, 1351-1364. [CrossRef]

47. Saunders, D.G.; Aves, S.J.; Talbot, N.J. Cell Cycle-Mediated Regulation of Plant Infection by the Rice Blast Fungus. Plant Cell 2010, 22, 497-507. [CrossRef]

48. Veneault-Fourrey, C.; Barooah, M.; Egan, M.; Wakley, G.; Talbot, N.J. Autophagic Fungal Cell Death Is Necessary for Infection by the Rice Blast Fungus. Science 2006, 312, 580-583. [CrossRef]

49. Xu, J.R.; Hamer, J.E. MAP Kinase and cAMP Signaling Regulate Infection Structure Formation and Pathogenic Growth in the Rice Blast Fungus Magnaporthe grisea. Genes Dev. 1996, 10, 2696-2706. [CrossRef]

50. Adachi, K.; Hamer, J.E. Divergent cAMP Signaling Pathways Regulate Growth and Pathogenesis in the Rice Blast Fungus Magnaporthe grisea. Plant Cell 1998, 10, 1361-1374. [CrossRef]

51. Ryder, L.S.; Talbot, N.J. Regulation of Appressorium Development in Pathogenic Fungi. Curr. Opin. Plant Biol. 2015, 26, 8-13. [CrossRef] [PubMed]

52. Eisenman, H.C.; Casadevall, A. Synthesis and Assembly of Fungal Melanin. Appl. Microbiol. Biotechnol. 2012, 93, 931-940. [CrossRef] [PubMed]

53. Pal, A.K.; Gajjar, D.U.; Vasavada, A.R. DOPA and DHN Pathway Orchestrate Melanin Synthesis in Aspergillus Species. Med. Mycol. 2014, 52, 10-18. [CrossRef] [PubMed]

54. Nosanchuk, J.D.; Casadevall, A. The Contribution of Melanin to Microbial Pathogenesis. Cell Microbiol. 2003, 5, $203-223$. [CrossRef]

55. Toledo, A.V.; Franco, M.E.E.; Yanil Lopez, S.M.; Troncozo, M.I.; Saparrat, M.C.N.; Balatti, P.A. Melanins in Fungi: Types, Localization and Putative Biological Roles. Physiol. Mol. Plant Pathol. 2017, 99, 2-6. [CrossRef]

56. Money, N.P.; Howard, R.J. Confirmation of a Link between Fungal Pigmentation, Turgor Pressure, and Pathogenicity Using a New Method of Turgor Measurement. Fungal Genet. Biol. 1996, 20, 217-227. [CrossRef]

57. Ludwig, N.; Löhrer, M.; Hempel, M.; Mathea, S.; Schliebner, I.; Menzel, M.; Kiesow, A.; Schaffrath, U.; Deising, H.B.; Horbach, R. Melanin Is Not Required for Turgor Generation but Enhances Cell-Wall Rigidity in Appressoria of the Corn Pathogen Colletotrichum graminicola. Mol. Plant Microbe Interact. 2014, 27, 315-327. [CrossRef]

58. Slot, J.C.; Rokas, A. Horizontal Transfer of a Large and Highly Toxic Secondary Metabolic Gene Cluster between Fungi. Curr. Biol. 2011, 21, 134-139. [CrossRef]

59. Tsuji, G.; Kenmochi, Y.; Takano, Y.; Sweigard, J.; Farrall, L.; Furusawa, I.; Horino, O.; Kubo, Y. Novel Fungal Transcriptional Activators, Cmr1p of Colletotrichum lagenarium and pig1p of Magnaporthe grisea, Contain Cys2His2 Zinc Finger and Zn(II)2Cys6 Binuclear Cluster DNA-Binding Motifs and Regulate Transcription of Melanin Biosynthesis Genes in a Developmentally Specific Manner. Mol. Microbiol. 2000, 38, 940-954. [CrossRef]

60. Cho, Y.; Srivastava, A.; Ohm, R.A.; Lawrence, C.B.; Wang, K.H.; Grigoriev, I.V.; Marahatta, S.P. Transcription Factor Amr1 Induces Melanin Biosynthesis and Suppresses Virulence in Alternaria brassicicola. PLoS Pathog. 2012, 8, e1002974. [CrossRef]

61. Wu, C. Heat Shock Transcription Factors: Structure and Regulation. Annu. Rev. Cell Dev. Biol. 1995, 11, 441-469. [CrossRef] 